\title{
Reproductive and menstrual factors and colorectal cancer incidence in the Women's Health Initiative Observational Study
}

\author{
Neil Murphy ${ }^{\star}, 1,2$, Linzhi Xu ${ }^{3}$, Alice Zervoudakis ${ }^{4}$, Xiaonan Xue $^{3}$, Geoffrey Kabat ${ }^{3}$, Thomas E Rohan $^{3}$, \\ Sylvia Wassertheil-Smoller ${ }^{3}$, Mary Jo O'Sullivan ${ }^{5}$, Cynthia Thomson $^{6}$, Catherine Messina ${ }^{7}$, Howard D Strickler $^{3}$ \\ and Marc J Gunter ${ }^{1,2}$

\begin{abstract}
${ }^{1}$ Department of Epidemiology and Biostatistics, School of Public Health, Imperial College, London, UK; ${ }^{2}$ Section of Nutrition and Metabolism, International Agency for Research on Cancer, Lyon, France; ${ }^{3}$ Department of Epidemiology and Population Health, Albert Einstein College of Medicine, Bronx, New York, NY, USA; ${ }^{4}$ Department of Oncology, Montefiore Medical Center, Bronx, New York, NY, USA; ${ }^{5}$ Department of Obstetrics and Gynecology, University of Miami, Miami, FL, USA; ${ }^{6}$ Mel and Enid Zuckerman College of Public Health, University of Arizona Canyon Ranch Center for Prevention \& Health Promotion, Tucson, AZ, USA and
\end{abstract} \\ ${ }^{7}$ Department of Preventive Medicine, Stony Brook University, Stony Brook, NY, USA
}

Background: Reproductive and menstrual factors have been evaluated as surrogates for long-term hormonal exposures in several prospective studies of colorectal cancer, yet findings have been conflicting.

Methods: The relation of reproductive and menstrual factors (self-reported via a reproductive history questionnaire) with incident colorectal cancer was investigated among women enrolled in the Women's Health Initiative Observational Study (WHI-OS), a longitudinal cohort of 93676 postmenopausal women (aged 50-79 years at enrolment) in which 1149 incident cases of colorectal cancer occurred over a median follow-up of 11.9 years. Multivariable Cox proportional hazards models that included established colorectal cancer risk factors were constructed to examine the association of colorectal cancer incidence with reproductive and menstrual factors.

Results: Having had two children (vs nulliparous: hazard ratio $(H R)=0.80,95 \%$ confidence interval (Cl): 0.64-0.99) was inversely associated with colorectal cancer risk. Compared with never users, ever use of oral contraceptives was associated with lower colorectal cancer risk ( $\mathrm{HR}=0.74,95 \% \mathrm{Cl}$ : $0.63-0.86)$; however, no relationship was observed for duration of oral contraceptives use (4 years vs 1 year: $\mathrm{HR}=0.94,95 \% \mathrm{Cl}: 0.67-1.32$ ). None of the remaining reproductive and menstrual factors was associated with colorectal cancer incidence.

Conclusions: Parity and prior use of oral contraceptives were associated with lower colorectal cancer risk in this cohort of postmenopausal women.

Colorectal cancer is the third most common cancer worldwide with more than one million new cases diagnosed each year (Ferlay et al, 2010). Incidence rates for colorectal cancer are lower among women compared with men across all age categories and it has been proposed that this is a consequence of higher oestrogen levels in women conferring protection (McMichael and Potter, 1980).
Consistent with this hypothesis are findings from a substantial body of epidemiologic literature that report a $20-40 \%$ lower incidence of colorectal cancer among users, than non-users, of postmenopausal hormone therapy (Hebert-Croteau, 1998; Grodstein et al, 1999; Nanda et al, 1999; Johnson et al, 2009; Green et al, 2012; Simon et al, 2012a). However, in contrast to

*Correspondence: Dr N Murphy; E-mail: murphyn@iarc.fr

Received 10 May 2016; revised 19 September 2016; accepted 25 September 2016; published online 29 November 2016

(c) 2017 Cancer Research UK. All rights reserved 0007-0920/17 
these observational results, the Women's Health Initiative Clinical Trial (WHI-CT) reported no effect of oestrogen-alone therapy on colorectal cancer risk (Chlebowski et al, 2004). In addition, administration of oestrogen plus progestin was initially found to yield a $44 \%$ reduction in risk of developing colorectal cancer compared with the placebo group (Chlebowski et al, 2004), but longer follow-up revealed this finding was a probable consequence of diagnostic delay (Simon et al, 2012b).

To date, five prospective studies have investigated the relationships between endogenous circulating oestrogens and colorectal cancer. The first of these studies was a case-cohort analysis in the WHI Observational Study, which reported a borderline statistically significant positive association between endogenous oestradiol levels and colorectal cancer incidence (Gunter et al, 2008). Three subsequent follow-up studies conducted in the New York University Women's Health Study (Clendenen et al, 2009), a joint Nurses' Health Study and Women's Health Study analysis (Lin et al, 2013), and an analysis in the Breast and Bone Follow-up to the Fracture Intervention Trial (B FIT; Falk et al, 2015) reported no association between oestradiol levels and colorectal cancer risk. Most recently, a nested case-control study in the WHI clinical trial nonintervention arms reported statistically significant inverse associations between colorectal cancer risk and total oestradiol, free oestradiol, and oestrone levels (Murphy et al, 2015).

Another approach to investigating the potential role of oestrogen in colorectal cancer development is to use reproductive history and menstrual factors as surrogates for long-term endogenous oestrogen exposure. Recently, two large prospective investigations have reported findings on the association of reproductive history and colorectal cancer risk. The European Prospective Investigation into Cancer and Nutrition study (EPIC), which analysed data from 337802 women and 1878 incident colorectal cancer cases, observed an inverse relation between oral contraceptive use and colorectal cancer but no statistically significant relationships for other reproductive factors (Tsilidis et al, 2010). In contrast, in the NIH-AARP Diet and Health Study, which evaluated 214162 postmenopausal women and more than 2000 colorectal cancer cases, age at menopause and age at birth of first child were positively associated with colorectal cancer incidence, while age at menarche and parity were inversely related to colorectal cancer (Zervoudakis et al, 2011). Other smaller prospective studies that investigated the relationships between reproductive factors and colorectal cancer risk have generally reported inconsistent results (Lin et al, 2007; Akhter et al, 2008; Kabat et al, 2008).

To further investigate the relation between reproductive history and colorectal cancer development and, by extension, the role of lifetime oestrogen exposure in relation to colorectal cancer, we evaluated data from the WHI Observational Study (WHI-OS) - a large prospective cohort of postmenopausal women with more than 15 years of follow-up and detailed information on reproductive and menstrual parameters, and other colorectal cancer risk factors.

\section{MATERIALS AND METHODS}

\section{Study population}

Women's Health Initiative Observational Study (WHI-OS). The WHI-OS is a longitudinal cohort of 93676 postmenopausal women aged 50-79 years who were recruited at 40 different clinical centres across the United States between 1 October 1993 and 31 December 1998 (The Women's Health Initiative Study Group, 1998). The study was approved by human subject's review committees at each of the participating institutions, and written informed consent was obtained from each study participant. Women were excluded from the current analysis if they reported a history of any cancer (except non-melanoma skin cancer) at enrolment $(n=1764)$. After these exclusions, 91912 women were included in the analysis.

Data collection and case identification. At baseline, women completed detailed questionnaires regarding medical and behavioural history, hormone and medication use, lifestyle and demographic factors. In the reproductive history questionnaire, women were asked about age at first menstrual period, age at last regular menstrual period, were they ever pregnant, number of pregnancies, number of pregnancies lasting at least 6 months, and number of live births and induced abortions. Participants were also asked whether they had ever taken oral contraceptives and, if so, the age at which they started and age of stopping use, how many years and months they used oral contraceptives, whether they had used oral contraceptives before a first full-term pregnancy and, if so, for how many years and months. Age at menopause was defined as the youngest age at which the participant experienced any of the following: last menstrual bleeding (all participants were at least 12 months post last menstrual period at baseline), removal of both ovaries, or initiation of menopausal hormone therapy. Age at first live birth was defined as the age at first pregnancy lasting 6 months or longer. A physical examination was conducted that included measurement of waist and hip circumference, and of height and weight. Incident cancer was ascertained through annual self-administered questionnaires or by self-reports between the annual questionnaires. Case status and detailed diagnosis were confirmed through centralised review of all pathology reports, discharge and trained adjudicator reports, operative and radiology reports, and tumour registry abstracts. Cases were coded according to National Cancer Institute Surveillance, Epidemiology and End-Results guidelines (Cancer Statistics Branch, 1992; US Dept of Health and Human Services, 1993). Participants with a history of colorectal cancer were excluded from the analysis.

Statistical analysis. The distributions of baseline characteristics between case participants and non-case participants were compared using the Wilcoxon rank sum test for continuous data and the Pearson $\chi^{2}$ test for categorical data. To examine the associations between reproductive and menstrual factors and risk of colorectal cancer, we estimated hazard ratios (HRs) using Cox proportional hazards regression modelling, with time from study enrolment, in days, as the underlying time metric. Individuals were censored at diagnosis of colorectal cancer, death or at the end of the current follow-up period, whichever occurred first. All multivariable models were adjusted for the following a priori-determined established colorectal cancer risk factors: age (categorised into 5 -year age groups; $<55$ (referent), $55-59,60-64,65-69$ or $\geqslant 70$ years); family history of colorectal cancer (defined as having a first-degree relative with colorectal cancer); race/ethnicity (white (referent), black, Hispanic or other); education level (less than college (referent), college or associate degree, higher than an associate degree); hormone therapy status (never (referent), former or current); a history of diabetes (no or yes); smoking status (never (referent), former or current) and body mass index (quartiles). Additional variables, including a history of colorectal polyps, use of nonsteroidal antiinflammatory drugs, physical activity, dietary calcium, fibre, folate, red meat intake and alcohol consumption were evaluated as potential covariates, but their inclusion in our a prioridetermined multivariable model outlined above did not alter the risk estimates and, therefore, they were not considered in subsequent models (data not shown). Statistical tests for 
Table 1. Selected baseline characteristics of the study population

\section{Variable}

Mean age, years (s.d.)

Ethnicity, no. (\%)

White

Black

Hispanic/Latino

Other

Missing

Mean body mass index $\left(\mathrm{kg} \mathrm{m}^{-2}\right.$; s.d.)

Mean dietary fibre intake (s.d.)

Mean dietary folate intake (s.d.)

Mean dietary calcium intake, $\mathrm{mg} \mathrm{day}^{-1}$ (s.d.)

Family history of colorectal cancer, no. (\%)

No

Missing

Alcohol drinking, no. (\%)

Non-drinker

Past drinker

$<1$ drink per week

$\geqslant 1$ drink per week

Missing

Smoking history, no. (\%)

Never smoked

Former smoker

Current smoker

Missing

Education level, no. (\%)

$<$ College

Some college

$>$ College

Missing

Diabetes, no. (\%)

No
Yes

Missing

Hormone therapy

Never used

Current user

Former user

Missing

Oral contraceptive use, no. (\%)

Never

Ever

Missing

Age at menarche (years)

$\leqslant 10$

$11-12$

13-14

$\geqslant 15$

Missing

Age at first child's birth (years)

$<20$

20-29

$\geqslant 30$

No children/missing

Age at last child's birth (years)

$$
<25
$$

$25-29$

30-34

35-39

$\geqslant 40$

No children/missing

Parity

Nulliparous

1 child only

2 children

3 children

$\geqslant 4$ children

Missing

Induced abortion

Never

Ever

Missing

Breastfed for $\geqslant 1$ month

No

Yes

Missing

Case participants $(N=1149)$ $66.6(6.9)$

$975(84.9)$

108 (9.4)

$25(2.2)$

39 (3.4)

$2(0.1)$

$28.1(5.9)$

$15.8(7.4)$

$466.8(218.1)$

$788.2(462.4)$

$834(72.6)$

$227(19.8)$

$88(7.6)$

$126(11.0)$

$220(19.1)$

397 (34.6)

401 (34.9)

$5(0.4)$

542 (47.2)

504 (43.9)

$88(7.7)$

15 (1.2)

356 (31.0)

$350(30.5)$

435 (37.9)

$8(0.6)$

1056 (91.9)

91 (7.9)

$2(0.2)$

577 (50.2)

$196(17.1)$

$374(32.6)$

$2(0.1)$

$839(73.0)$

310 (27.0)

$0(0)$

40 (3.5)

315 (27.4)

420 (36.6)

$192(16.7)$

182 (15.8)

123 (10.7)

664 (57.8)

$92(8.0)$

270 (23.5)

$112(9.7)$

258 (22.5)

$258(22.5)$
$275(23.9)$

178 (15.5)

49 (4.3)

$277(24.1)$

$158(13.8)$

$100(8.7)$

269 (23.4)

$265(23.1)$

$351(30.5)$

$6(0.5)$

$864(75.2)$

$82(7.1)$

$203(17.7)$

$567(49.3)$

$563(50.0)$

19 (1.7)

Non-case participants $(N=90763)$

$P$ $63.5(7.4)$

$75636(83.3)$

7336 (8.1)

3488 (3.8)

$4049(4.5)$

$254(0.3)$

$27.3(5.9)$

$16.3(7.4)$

483.8 (223.9)

819.4 (223.9)

$69220(76.3)$

$13750(15.1)$

$7793(8.6)$

$10133(11.2)$

$16983(18.7)$

28563 (31.5)

34523 (38.0)

$561(0.6)$

45730 (50.4)

38261 (42.2)

5600 (6.2)

$1172(1.2)$

28105 (31.0)

23981 (26.4)

37944 (41.8)

$733(0.8)$

85576 (94.3)

5097 (5.6)

$90(0.1)$

36633 (40.4)

$13442(14.8)$

40613 (44.7)

$75(0.1)$

54158 (59.7)

36605 (40.3)

0 (0)

2897 (3.2)

23375 (25.8)

$32814(36.2)$

16845 (18.6)

14382 (16.2)

10208 (11.2)

52991 (58.4)

6981 (7.7)

20583 (22.7)

9030 (9.9)

$23032(25.3)$

23064 (25.4)

11855 (13.1)

3189 (3.5)

20593 (22.8)

$11513(12.7)$

8236 (9.1)

23774 (26.2)

21782 (24.0)

24958 (27.5)

$500(0.5)$

$69404(76.5)$

$6782(7.5)$

$14577(16.0)$

$45705(50.4)$

$44110(48.6)$

$948(1.0)$ 


\begin{tabular}{|c|c|c|c|}
\hline Variable & Case participants $(N=1149)$ & Non-case participants $(N=90763)$ & $P$ \\
\hline $\begin{array}{l}\text { Age at menopause (years) } \\
<40 \\
40-44 \\
45-49 \\
50-54 \\
\geqslant 55 \\
\text { Missing }\end{array}$ & $\begin{array}{l}132(11.5) \\
152(13.2) \\
269(23.4) \\
364(31.7) \\
135(11.7) \\
97(8.5)\end{array}$ & $\begin{array}{l}10707(11.8) \\
12163(13.4) \\
20685(22.8) \\
29069(32.0) \\
9180(10.1) \\
8959(9.9)\end{array}$ & 0.55 \\
\hline $\begin{array}{l}\text { Hysterectomy } \\
\text { No } \\
\text { Yes } \\
\text { Missing }\end{array}$ & $\begin{array}{c}673(58.6) \\
476(41.4) \\
0(0)\end{array}$ & $\begin{array}{c}52850(58.2) \\
37828(41.7) \\
85(0.1) \\
\end{array}$ & 0.84 \\
\hline $\begin{array}{l}\text { Bilateral oophorectomy } \\
\text { No } \\
\text { Yes } \\
\text { Missing }\end{array}$ & $\begin{array}{c}886(77.1) \\
233(20.3) \\
30(2.6)\end{array}$ & $\begin{array}{c}70702(77.9) \\
18243(20.1) \\
1818(2.0) \\
\end{array}$ & 0.8 \\
\hline
\end{tabular}

trend were calculated by entering the ordinal reproductive and menstrual facts variable into the models as a continuous variable.

We also performed analyses stratified by waist circumference $(<82.5$ (median) $v s \geqslant 82.5 \mathrm{~cm})$ and ever use of hormone therapy (never use $v s$ ever use). To test for statistically significant differences in the association between the reproductive factors and risk of colorectal cancer between strata of waist circumference and ever use of hormone therapy, we compared the multivariable model for the association of the reproductive factor of interest with colorectal cancer risk with a subsequent model that included the reproductive factor and an interaction term for that variable and the stratified factor. The difference between the two models was evaluated using the likelihood ratio test. All tests of statistical significance were two sided, and $P$-values less than 0.05 were considered statistically significant. The proportionality of the Cox model was verified by examination of the residual plots. All analyses were performed using SAS 9.3 (SAS Institute, Cary, NC, USA).

\section{RESULTS}

Participant characteristics. During a median follow-up period of 11.9 years, 1149 postmenopausal women were diagnosed with colorectal cancer, of which 959 were colon cancers and 147 were rectal cancers (43 cases did not have information on subsite location). The baseline characteristics of the colorectal cancer cases and non-cases are shown in Table 1. In brief, compared with noncase participants, colorectal cancer case participants were older, had a higher BMI, were less likely to be educated above college level, and more likely to have a positive family history of colorectal cancer, to be current or former smokers, and to be diabetic. Colorectal cancer case participants also reported consuming less dietary fibre, folate and calcium, and were less likely to have used oral hormone therapy, and more likely to have used oral contraceptives compared with non-case participants.

Associations with colorectal cancer. Table 2 presents ageadjusted and multivariable-adjusted $\mathrm{HRs}$ and $95 \%$ confidence intervals (CIs) for associations between reproductive factors and the risk of colorectal cancer. Parity was inversely associated with incident colorectal cancer in the multivariable models. For example, women who reported giving birth to two children had a $20 \%$ reduction in colorectal cancer incidence compared with nulliparous women ( $\mathrm{HR}=0.80,95 \% \mathrm{CI}: 0.64-0.99)$. The HRs for colorectal cancer when comparing nulliparous women with those who reported giving birth to three children and four or more children were very similar and of borderline statistical significance, suggesting a possible threshold effect. When all three categories were collapsed to form a single joint parameter of $\geqslant 2$ children, the HR for comparing $\geqslant 2$ children with nulliparous women was statistically significant $(\mathrm{HR}=0.82,95 \% \mathrm{CI}: 0.68-0.98$; data not tabulated). Older age at menarche was inversely associated with colorectal cancer risk in univariate models (HR for $\geqslant 15$ vs 11-12 years $=0.81 ; 95 \%$ CI: $0.67-0.98)$ but was no longer significant in the multivariable model ( $\mathrm{HR}$ for $\geqslant 15$ vs $11-12$ years $=0.82$; $95 \%$ CI: $0.67-1.00)$. Prior oral contraceptive use, but not duration of use, was inversely associated with colorectal cancer risk ( $\mathrm{HR}=0.74,95 \%$ CI: $0.63-0.86)$. We did not observe statistically significant associations between age at menopause, age at birth of first or last child, breastfeeding, abortion, hysterectomy or oophorectomy status and risk of colorectal cancer. Simultaneous inclusion of each of the reproductive factors in the multivariable model did not meaningfully alter the associations of these parameters with colorectal cancer risk, and neither did restricting analyses to either colon or rectal cancer, and proximal colon or distal colon cancer (data not shown).

None of the associations between the reproductive factors and risk of colorectal cancer differed according to waist circumference (data not shown) strata and ever use of hormone therapy (Table 3; all $P_{\text {interaction }}>0.05$ ). For age at menarche, a statistically significant lower colorectal cancer risk was observed for never users of hormone therapy (HR for $\geqslant 15$ vs 11-12 years $=0.72 ; 95 \%$ CI: $\left.0.54-0.96 ; P_{\text {trend }}=0.10\right)$, but not for ever users (HR for $\geqslant 15$ vs $11-12$ years $=0.92$; 95\% CI: $0.69-1.22$; $\left.P_{\text {trend }}=0.90\right)$, although this heterogeneity was not statistically different $\left(P_{\text {interaction }}=0.30\right)$.

\section{DISCUSSION}

In this prospective study of postmenopausal women, we observed statistically significant inverse associations for parity and use of oral contraceptives with colorectal cancer development. The remaining reproductive and menstrual factors considered were not associated with colorectal cancer risk. These findings are partly consistent with prior prospective investigations of reproductive patterns and colorectal cancer incidence and suggest that the hormonal changes associated with pregnancy and use of oral contraceptives may be relevant for colorectal tumorigenesis.

In the current analysis, having given birth to at least two children was associated with a near $20 \%$ reduction in colorectal cancer risk compared with that for women who remained nulliparous. These data are consistent with findings from a previous analysis in the NIH-AARP study which reported a similar inverse association, albeit restricted to women who had not used hormone therapy (Zervoudakis et al, 2011). Pregnancy is associated with significant endocrinologic and metabolic changes 
Table 2. Hazard ratios and $95 \%$ confidence intervals for the association of reproductive and menstrual factors with colorectal cancer incidence among women enrolled in the WHI-OS

\begin{tabular}{|c|c|c|c|}
\hline Factor & $N$ cases & Age-adjusted HR (95\% Cl) & Multivariable $\mathrm{HR}^{\mathrm{a}}(95$ \\
\hline \multicolumn{4}{|c|}{ Age at menarche (years) } \\
\hline$\leqslant 10$ & 40 & $1.16(0.82-1.63)$ & $1.09(0.76-1.56)$ \\
\hline $11-12$ & 315 & 1.00 (referent) & 1.00 (referent) \\
\hline $13-14$ & 420 & $0.91(0.78-1.06)$ & $0.95(0.81-1.11)$ \\
\hline$\geqslant 15$ & 192 & $0.81(0.67-0.98)$ & $0.82(0.67-1.00)$ \\
\hline$P$-trend & & 0.08 & 0.2 \\
\hline
\end{tabular}

\begin{tabular}{|c|c|c|c|}
\hline \multicolumn{4}{|c|}{ Age at first child's birth (years) } \\
\hline$<20$ & 123 & 1.00 (referent) & 1.00 (referent) \\
\hline $20-29$ & 664 & $0.88(0.72-1.08)$ & $0.98(0.78-1.23)$ \\
\hline$\geqslant 30$ & 92 & $0.85(0.64-1.14)$ & $0.96(0.70-1.31)$ \\
\hline$P$-trend & & 0.45 & 0.96 \\
\hline
\end{tabular}

\begin{tabular}{|c|c|c|c|}
\hline \multicolumn{4}{|c|}{ Age at last child's birth (years) } \\
\hline$<25$ & 112 & 1.00 (referent) & 1.00 (referent) \\
\hline $25-29$ & 258 & $0.83(0.66-1.05)$ & $0.95(0.74-1.22)$ \\
\hline $30-34$ & 275 & $0.77(0.61-0.97)$ & $0.88(0.68-1.13)$ \\
\hline $35-39$ & 178 & $0.87(0.67-1.11)$ & $0.94(0.71-1.24)$ \\
\hline$\geqslant 40$ & 49 & $0.89(0.62-1.26)$ & $0.91(0.62-1.34)$ \\
\hline$P$-trend & & 0.25 & 0.86 \\
\hline
\end{tabular}

\begin{tabular}{|c|c|c|c|}
\hline Pregnancy & & & \\
\hline Never & 123 & 1.00 (referent) & 1.00 (referent) \\
\hline Ever & 1025 & $0.88(0.73-1.07)$ & $0.82(0.67-1.00$ \\
\hline
\end{tabular}

\section{Parity}

Nulliparous

1 child only

2 children

3 children

$\geqslant 4$ children

$P$-trend

$0.88(0.73-1.07)$

$0.82(0.67-1.00)$

\section{Induced abortion}

Never

Ever

\begin{tabular}{c|c}
158 & 1.00 (referent) \\
100 & $0.89(0.69-1.15)$ \\
269 & $0.80(0.65-0.98)$ \\
265 & $0.81(0.66-1.00)$ \\
351 & $0.90(0.74-1.09)$ \\
& 0.2
\end{tabular}

1.00 (referent)

$0.86(0.65-1.13)$

$0.80(0.64-0.99)$

$0.80(0.65-1.00)$

$0.85(0.69-1.04)$

0.2

0.28

\begin{tabular}{|l|r|}
\hline Breastfed for $\geqslant 1$ month \\
\hline No & 567 \\
Yes & 563 \\
\hline Age at menopause (years) \\
\hline$<40$
\end{tabular}

$40-44$

$45-49$

$50-54$

$\geqslant 55$

$P$-trend

\begin{tabular}{l|l}
864 & 1.00 (referent)
\end{tabular}

\begin{tabular}{l|l}
82 & $1.13(0.89-1.44)$
\end{tabular}

1.00 (referent)

$1.12(0.87-1.45)$

\begin{tabular}{l|l|l}
567 & 1.00 (referent) & 1.00 (referent) \\
563 & $0.90(0.79-1.01)$ & $0.95(0.83-1.08)$
\end{tabular}

\section{Hysterectomy}

\begin{tabular}{|c|c|c|c|}
\hline $\begin{array}{l}\text { No } \\
\text { Yes }\end{array}$ & $\begin{array}{l}673 \\
476\end{array}$ & $\begin{array}{l}1.00 \text { (referent) } \\
0.97(0.86-1.10)\end{array}$ & $\begin{array}{l}1.00 \text { (referent) } \\
1.06(0.93-1.22)\end{array}$ \\
\hline \multicolumn{4}{|c|}{ Bilateral oophorectomy } \\
\hline $\begin{array}{l}\text { No } \\
\text { Yes }\end{array}$ & $\begin{array}{l}886 \\
233\end{array}$ & $\begin{array}{l}1.00 \text { (referent) } \\
0.97(0.84-1.13)\end{array}$ & $\begin{array}{l}1.00 \text { (referent) } \\
1.09(0.93-1.28)\end{array}$ \\
\hline \multicolumn{4}{|c|}{ Age at oophorectomy (years) } \\
\hline $\begin{array}{l}\leqslant 34 \\
35-39 \\
40-44 \\
45-49 \\
\geqslant 50 \\
P \text {-trend }\end{array}$ & $\begin{array}{r}46 \\
57 \\
67 \\
65 \\
111\end{array}$ & $\begin{array}{l}1.00 \text { (referent) } \\
1.48(1.00-2.20) \\
1.20(0.82-1.77) \\
0.93(0.63-1.38) \\
1.13(0.80-1.61) \\
0.12\end{array}$ & $\begin{array}{l}1.00 \text { (referent) } \\
1.51(0.99-2.31) \\
1.28(0.84-1.94) \\
1.07(0.70-1.63) \\
1.37(0.94-2.00) \\
0.22\end{array}$ \\
\hline \multicolumn{4}{|c|}{ Oral contraceptive use } \\
\hline $\begin{array}{l}\text { Never } \\
\text { Ever }\end{array}$ & $\begin{array}{l}839 \\
310\end{array}$ & $\begin{array}{l}1.00 \text { (referent) } \\
0.72(0.62-0.83)\end{array}$ & $\begin{array}{l}1.00 \text { (referent) } \\
0.74(0.63-0.86)\end{array}$ \\
\hline \multicolumn{4}{|c|}{ Duration of OC use (years) } \\
\hline $\begin{array}{l}1 \\
2 \\
3 \\
4 \\
P \text {-trend }\end{array}$ & $\begin{array}{l}96 \\
58 \\
83 \\
73\end{array}$ & $\begin{array}{l}1.00 \text { (referent) } \\
1.08(0.77-1.52) \\
1.19(0.87-1.61) \\
0.94(0.68-1.29) \\
0.52\end{array}$ & $\begin{array}{l}1.00 \text { (referent) } \\
1.14(0.80-1.62) \\
1.18(0.85-1.63) \\
0.94(0.67-1.32) \\
0.55\end{array}$ \\
\hline
\end{tabular}


Table 3. Hazard ratios and $95 \%$ confidence intervals for the association of reproductive and menstrual factors with colorectal cancer incidence stratified by hormone therapy use among women enrolled in the WHI-OS

Hormone therapy use

\begin{tabular}{|l|c}
\cline { 2 - 2 } & Never use \\
\hline Factor & Multivariable $\left.\mathbf{H R}^{\mathrm{a}} \mathbf{( 9 5 \%} \mathbf{C}\right)$ \\
\hline Age at menarche (years) & \\
\hline$\leqslant 10$ & $1.15(0.71-1.85)$ \\
$11-12$ & $1.00($ referent) \\
$13-14$ & $0.89(0.71-1.11)$ \\
$\geqslant 15$ & $0.72(0.54-0.96)$ \\
$P$-trend & 0.1 \\
\hline P-interaction &
\end{tabular}

\section{Age at first child's birth (years)}

$<20$

$20-29$

$\geqslant 30$

$P$-trend

1.00 (referent)

$0.99(0.71-1.38)$

$0.88(0.56-1.38)$

0.79

$P$-interaction

\section{Age at last child's birth (years)}

\section{$<25$}

25-29

30-34

35-39

$\geqslant 40$

$P$-trend

$P$-interaction

1.00 (referent)

$0.96(0.65-1.42)$

$0.91(0.62-1.35)$

$1.02(0.68-1.53)$

$0.81(0.47-1.41)$
0.88

\section{Ever use}

\section{Pregnancy}

Never

Ever

$P$-interaction

1.00 (referent) $0.84(0.63-1.11)$

\section{Parity}

Nulliparous

1 child only

2 children

3 children

$\geqslant 4$ children

$P$-trend

$P$-interaction

1.00 (referent)

$0.96(0.66-1.39)$

$0.76(0.56-1.03)$

$0.82(0.61-1.11)$

$0.76(0.57-1.01)$ 0.27

1.00 (referent)

$0.97(0.71-1.33)$

1.08 (0.69-1.67)

$1.00(0.58-1.74)$

1.00 (referent)

$1.02(0.81-1.28)$

$0.92(0.69-1.22)$

0.9

0.3

\section{Induced abortion}

Never

Ever

$P$-interaction

$1.22(0.85-1.75)$

\section{Breast fed for $\geqslant 1$ month}

\begin{tabular}{|r|r} 
No & 1.00 (referent) \\
\hline
\end{tabular}

Yes

P-interaction

$0.92(0.76-1.10)$

\section{Age at menopause (years)}

$$
0.84
$$

$<40$

40-44

45-49

50-54

$\geqslant 55$

$P$-trend

$P$-interaction

\section{Hysterectomy}

No
Yes

$P$-interaction

1.00 (referent)

$0.93(0.63-1.37)$

$0.89(0.63-1.27)$

$0.80(0.57-1.13)$

$0.95(0.64-1.42)$

0.64

1.00 (referent)

$1.23(1.01-1.50)$

Age at oophorectomy (years)

$\leqslant 34$

35-39

40-44

$45-49$

$\geqslant 50$

$P$-trend

$P$-interaction

Oral contraceptive use

Never

Ever

P-interaction
1.00 (referent)

1.99 (1.07-3.69)

$1.54(0.81-2.92)$

$1.38(0.72-2.66)$

$1.13(0.62-2.07)$

0.19

$0.64(0.51-0.81)$
1.00 (referent)

$0.94(0.67-1.30)$

$0.84(0.60-1.18)$

$0.85(0.57-1.25)$

$1.08(0.63-1.85)$

0.74

\subsection{6}

1.00 (referent)

0.80 (0.59-1.07)

0.77

1.00 (referent)

$0.77(0.51-1.16)$

$0.83(0.61-1.13)$

$0.79(0.58-1.08)$

$0.94(0.70-1.28)$

0.41

0.49

1.00 (referent)
$1.03(0.71-1.49)$

1.00 (referent)

0.97 (0.81-1.17)

0.58

1.00 (referent)

$0.81(0.57-1.16)$

$1.06(0.78-1.43)$

$0.99(0.74-1.34)$

$0.98(0.67-1.41)$

0.6

\subsection{8}

1.00 (referent)
$0.90(0.75-1.08)$

1.00 (referent)

$1.23(0.69-2.20)$

$1.13(0.66-1.96)$

$0.90(0.52-1.56)$

$1.40(0.86-2.30)$

0.27

0.33

0.82 (0.67-1.01) 


\begin{tabular}{|c|c|c|}
\hline & \multicolumn{2}{|c|}{ Hormone therapy use } \\
\hline Factor & Multivariable $\mathrm{HR}^{\mathrm{a}}(95 \% \mathrm{Cl})$ & Multivariable $\mathrm{HR}^{\mathrm{a}}(95 \% \mathrm{Cl})$ \\
\hline \multicolumn{3}{|c|}{ Duration of $O C$ use (years) } \\
\hline $\begin{array}{l}1 \\
2 \\
3 \\
4 \\
P \text {-trend }\end{array}$ & $\begin{array}{c}1.00 \text { (referent) } \\
0.79(0.42-1.47) \\
1.58(0.98-2.54) \\
0.71(0.39-1.31) \\
0.03\end{array}$ & $\begin{array}{c}1.00 \text { (referent) } \\
1.38(0.89-2.13) \\
0.94(0.61-1.47) \\
1.03(0.68-1.57) \\
0.37\end{array}$ \\
\hline$P$-interaction & \multicolumn{2}{|c|}{0.03} \\
\hline
\end{tabular}

that may be relevant for colorectal cancer risk. For example, during gestation, ovarian production of oestradiol ceases and oestrone becomes the predominant circulating oestrogen (Kronenberg and Williams, 2010). In experimental models, oestrone has been shown to exert antiproliferative effects in colorectal cancer cell lines (English et al, 1999), while oestradiol has been demonstrated to have proliferative properties in same tissues (Di Domenico et al, 1996). Consistent with these findings, in a recent nested casecontrol study conducted in the Women's Health Initiative Clinical Trial non-intervention arms, we reported a significant inverse association between circulating oestrone levels (odds ratio $(\mathrm{OR})_{\text {quartile }} 4$-quartile $1=0.44,95 \%$ CI: $\left.0.28-0.68 ; P_{\text {trend }}=0.001\right)$, while total oestradiol levels were more weakly related to colorectal cancer development and without a statistically significant trend between quartiles (Murphy et al, 2015). It is therefore possible that the inverse relationship between parity and colorectal cancer observed in the current study may be a consequence of elevated oestrone exposure during pregnancy. Other changes to the hormonal milieu during pregnancy may also be relevant to our findings, such as a continuous production of progesterone, which has been shown to oppose the mitogenic effects of oestrogen in the reproductive tract (Kronenberg and Williams, 2010). Whether a similar effect would occur in the colonic tissue, in which progesterone receptors are expressed (Oshima et al, 1999), is unknown. Overall, additional studies measuring circulating endogenous sex hormones are warranted to investigate whether the oestrogenic and progestogenic environment caused by pregnancy influences colorectal cancer risk after menopause. Such analyses may inform on whether the inverse relationship observed between parity and colorectal cancer in the current study as well as in the NIH-AARP analysis has a biological basis.

Similar to the results of the NIH-AARP analysis, we observed a lower risk of colorectal cancer among women who underwent menarche at a later age but only among never users of hormone therapy (Zervoudakis et al, 2011). Although the linear trend across menarche age groups was not statistically significant, this may have been a consequence of a lack of power for this subgroup analysis. Age at menarche may be an indicator of the duration of exposure to cyclic ovarian function and lifetime oestrogenic exposure. However, cross-sectional analyses of premenopausal and postmenopausal women have found no relationships between age at menarche and circulating oestrogen (Bernstein et al, 1991; Hankinson et al, 1995), which suggests that other non-oestrogenic pathways may explain the inverse association between age at menarche and colorectal cancer. Early pubertal development has been related to higher early life and adult adiposity (Chen et al, 2011; Baek et al, 2015; Dreyfus et al, 2015), insulin resistance (Chen et al, 2011; Baek et al, 2015; Dreyfus et al, 2015), and prediabetes and diabetes (Elks et al, 2013; Baek et al, 2015; Dreyfus et al, 2015), all of which are established positive risk factors for colorectal cancer (Pischon et al, 2006; Gunter et al, 2008; Thrift et al, 2015; Tsilidis et al, 2015; Zhang et al, 2015). A recent analysis in the Nurses' Health Study reported positive relationships between estimated body fatness in childhood and adolescence and colorectal cancer risk, independent of adult BMI (Zhang et al, 2015). Our observed inverse relationship between age at menarche and colorectal cancer risk may, therefore, be a consequence of residual confounding, or could be mediated by early life adiposity and associated metabolic abnormalities, such as hyperinsulinaemia and insulin resistance. Future analyses with larger numbers of cases may be able to investigate the interrelationships between menarcheal age, lifecourse adiposity and colorectal cancer development.

The observation of a statistically significant inverse relationship between age at menarche and colorectal cancer only among never users of hormone therapy is also notable. Hormone therapy use has been consistently linked with lower colorectal cancer risk (HebertCroteau, 1998; Grodstein et al, 1999; Nanda et al, 1999; Johnson et al, 2009; Green et al, 2012; Simon et al, 2012a), and may counter the adverse metabolic effects of early menarche, explaining why we did not observe an association with colorectal cancer in this subgroup.

The lower colorectal cancer risk observed among users of oral contraceptives in the current analysis is consistent with a recent meta-analysis of eight cohort studies, which reported a pooled $14 \%$ lower colorectal cancer risk (relative risk $(\mathrm{RR})=0.86,95 \% \mathrm{CI}$ : 0.80-0.91) for ever users when compared with never users (Luan et al, 2015). However, we did not observe any relationship for shorter-term duration of oral contraceptive use $(4+$ years). Similarly, in the EPIC study, in which lower colorectal cancer risk was found for oral contraceptive users when compared with never users (Tsilidis et al, 2010), no relationship was observed for longerterm duration of oral contraceptive use $(10+$ years $)$. The absence of a relationship by duration of use may be a consequence of the variable formulations of oral contraceptives used among women within and between studies. In the current study, we did not have information on the formulations of oral contraceptives that had been taken throughout participants' reproductive life. More detailed information on formulation may also inform on potential alteration in folate status as early oral contraceptives have been associated with folate inadequacy (Shojania, 1982) and efforts to correct this with folic acid supplementation were with oral contraceptive 'pill pack' use, an approach that while primarily designed to reduce folate insufficiency related to oral contraceptives, may have exerted an antitumorigenic effect.

Unlike the NIH-AARP study (Zervoudakis et al, 2011), but similar to the EPIC and Nurses' Health Study analyses (Martinez et al, 1997; Tsilidis et al, 2010), we did not observe a positive relationship for later age at menopause and colorectal cancer risk. We also observed null associations for colorectal cancer risk and age at birth of first and last child, pregnancy, induced abortion, breastfeeding, hysterectomy and bilateral oophorectomy, consistent with most prior prospective studies (Lin et al, 2007; Sakauchi 
and Japan Collaborative Cohort Study for Evaluation of Cancer, 2007; Kabat et al, 2008; Tsilidis et al, 2010).

The strengths of this study include the comprehensive analysis of reproductive and menstrual patterns in a large well-characterised prospective cohort of more than 90000 postmenopausal women and with more than 1000 colorectal cancer cases verified by tumour registry data and the relatively long follow-up of the study participants. The large sample size enabled us to perform stratified analyses with adequate statistical power, which allowed the assessment of women according to waist circumference strata or hormone therapy use, two factors that could have a confounding and effect modifying influence on the association between reproductive history and colorectal cancer. A possible limitation of this analysis is that all of the primary variables of interest were based on self-reported reproductive history and thus we cannot exclude the possibility of bias related to inaccurate recall; however, self-reported reproductive history has shown good agreement with medical records in validation studies (Hankinson et al, 1995; Chubak et al, 2004). Additionally, we lacked information on oral contraceptive formulations which would have been informative for understanding potential mechanisms. Finally, we cannot rule out the possibility that survivor bias influenced the observed results, in particular for early life exposures such as age at menarche, though we did not detect any effect modification by age suggesting that the findings were not different in younger or older women

In conclusion, having given birth to at least two children and ever use of oral contraceptives were associated with lower colorectal cancer risk. Further research into the biological mechanisms underlying these relationships is warranted and may provide insight into potential preventive measures for colorectal cancer in postmenopausal women.

\section{ACKNOWLEDGEMENTS}

National Institutes of Health, National Heart Lung and Blood Institute, contract number HHSN268200900010C (to PI, MG). The WHI program is funded by the National Heart, Lung, and Blood Institute, National Institutes of Health, US Department of Health and Human Services through contracts HHSN268201100046C, HHSN268201600003C, HHSN268201600002C, HHSN26820160 0004C, HHSN268201600001C and HHSN271201100004C. WHI Investigators: Program Office: National Heart, Lung, and Blood Institute, Bethesda, MD, USA: Jacques Rossouw, Shari Ludlam, Dale Burwen, Joan McGowan, Leslie Ford and Nancy Geller. Clinical Coordinating Center: Fred Hutchinson Cancer Research Center, Seattle, WA, USA: Garnet Anderson, Ross Prentice, Andrea LaCroix and Charles Kooperberg. Investigators and Academic Centers: Brigham and Women's Hospital, Harvard Medical School, Boston, MA, USA: JoAnn E Manson; MedStar Health Research Institute/Howard University, Washington, DC, USA: Barbara V Howard; Stanford Prevention Research Center, Stanford, CA, USA: Marcia L Stefanick; The Ohio State University, Columbus, OH, USA: Rebecca Jackson; University of Arizona, Tucson/Phoenix, AZ, USA: Cynthia A Thomson; University at Buffalo, Buffalo, NY, USA: Jean Wactawski-Wende; University of Florida, Gainesville/Jacksonville, FL, USA: Marian Limacher; University of Iowa, Iowa City/Davenport, IA, USA: Robert Wallace; University of Pittsburgh, Pittsburgh, PA, USA: Lewis Kuller; Wake Forest University School of Medicine, Winston-Salem, NC, USA: Sally Shumaker.

\section{CONFLICT OF INTEREST}

The authors declare no conflict of interest.

\section{REFERENCES}

Akhter M, Inoue M, Kurahashi N, Iwasaki M, Sasazuki S, Tsugane S, for the JPHC Study Group (2008) Reproductive factors, exogenous female hormone use and colorectal cancer risk: the Japan Public Health Centerbased Prospective Study. Eur J Cancer Prev 17(6): 479-571.

Baek TH, Lim NK, Kim MJ, Lee J, Ryu S, Chang Y, Choi Y, Park HY (2015) Age at menarche and its association with dysglycemia in Korean middleaged women. Menopause 22(5): 542-548.

Bernstein L, Pike MC, Ross RK, Henderson BE (1991) Age at menarche and estrogen concentrations of adult women. Cancer Causes Control 2(4): 221-225.

Cancer Statistics Branch, Surveillance Program Division of Cancer Prevention and Controlm National Cancer Institute. The SEER Program Code Manual. NIH Publication No. 92-1999 (1992) US Department of Health and Human Services, Public Health Service, National Institutes of Health.

Chen L, Zhang C, Yeung E, Ye A, Mumford SL, Wactawski-Wende J, Schisterman EF (2011) Age at menarche and metabolic markers for type 2 diabetes in premenopausal women: The BioCycle Study. J Clin Endocrinol Metab 96(6): E1007-E1012.

Chlebowski RT, Wactawski-Wende J, Ritenbaugh C, Hubbell FA, Ascensao J, Rodabough RJ, Rosenberg CA, Taylor VM, Harris R, Chen C, AdamsCampbell LL, White E (2004) Estrogen plus progestin and colorectal cancer in postmenopausal women. N Engl J Med 350(10): 991-1004.

Chubak J, Tworoger SS, Yasui Y, Ulrich CM, Stanczyk FZ, McTiernan A (2004) Associations between reproductive and menstrual factors and postmenopausal sex hormone concentrations. Cancer Epidemiol Biomarkers Prev 13(8): 1296-1301.

Clendenen TV, Koenig KL, Shore RE, Levitz M, Arslan AA, Zeleniuch-Jacquotte A (2009) Postmenopausal levels of endogenous sex hormones and risk of colorectal cancer. Cancer Epidemiol Biomarkers Prev 18(1): 275-281.

Di Domenico M, Castoria G, Bilancio A, Migliaccio A, Auricchio F (1996) Estradiol activation of human colon carcinoma-derived Caco-2 cell growth. Cancer Res 56(19): 4516-4521.

Dreyfus J, Jacobs J, Mueller N, Schreiner PJ, Moran A, Carnethon MR, Demerath EW (2015) Age at menarche and cardiometabolic risk in adulthood: the coronary artery risk development in young adults study. J Pediatr 167(2): 344-352.

Elks CE, Ong KK, Scott RA, van der Schouw YT, Brand JS, Wark PA, Amiano P, Balkau B, Barricarte A, Boeing H, Fonseca-Nunes A, Franks PW, Grioni S, Halkjaer J, Kaaks R, Key TJ, Khaw KT, Mattiello A, Nilsson PM, Overvad K, Palli D, Quirós JR, Rinaldi S, Rolandsson O, Romieu I, Sacerdote C, Sánchez MJ, Spijkerman AMW, Tjonneland A, Tormo MJ, Tumino R, van der A DL, Forouhi NG, Sharp SJ, Langenberg C, Riboli E, Wareham NJ, The InterAct Consortium (2013) Age at menarche and type 2 diabetes risk: The EPIC-InterAct study. Diabetes Care 36(11): 3526-3534.

English MA, Kane KF, Cruickshank N, Langman MJS, Stewart PM, Hewison M (1999) Loss of estrogen inactivation in colonic cancer. J Clin Endocrinol Metab 84(6): 2080-2085.

Falk RT, Dallal CM, Lacey JV, Bauer DC, Buist DSM, Cauley JA, Hue TF, LaCroix AZ, Tice JA, Pfeiffer RM, Xu X, Veenstra TD, Brinton LA (2015) Estrogen metabolites are not associated with colorectal cancer risk in postmenopausal women. Cancer Epidemiol Biomarkers Prev 24(9): 1419-1422.

Ferlay J, Shin HR, Bray F, Forman D, Mathers C, Parkin DM (2010) Estimates of worldwide burden of cancer in 2008: GLOBOCAN 2008. Int $J$ Cancer 127(12): 2893-2917.

Green J, Czanner G, Reeves G, Watson J, Wise L, Roddam A, Beral V (2012) Menopausal hormone therapy and risk of gastrointestinal cancer: nested case - control study within a prospective cohort, and meta-analysis. Int $J$ Cancer 130(10): 2387-2396.

Grodstein F, Newcomb PA, Stampfer MJ (1999) Postmenopausal hormone therapy and the risk of colorectal cancer: a review and meta-analysis. Am J Med 106(5): 574-582.

Gunter MJ, Hoover DR, Yu H, Wassertheil-Smoller S, Rohan TE, Manson JE, Howard BV, Wylie-Rosett J, Anderson GL, Ho GYF, Kaplan RC, Li J, Xue X, Harris TG, Burk RD, Strickler HD (2008) Insulin, insulin-like growth factor-I, endogenous estradiol, and risk of colorectal cancer in postmenopausal women. Cancer Res 68(1): 329-337.

Hankinson SE, Colditz GA, Hunter DJ, Manson JE, Willett WC, Stampfer MJ, Longcope C, Speizer FE (1995) Reproductive factors and family history of breast cancer in relation to plasma estrogen and prolactin levels in 
postmenopausal women in the Nurses' Health Study (United States). Cancer Causes Control 6(3): 217-224.

Hebert-Croteau N (1998) A meta-analysis of hormone replacement therapy and colon cancer in women. Cancer Epidemiol Biomarkers Prev 7(8): 653-659.

Johnson JR, Lacey JV, Lazovich D, Geller MA, Schairer C, Schatzkin A, Flood A (2009) Menopausal hormone therapy and risk of colorectal cancer. Cancer Epidemiol Biomarkers Prev 18(1): 196-203.

Kabat GC, Miller AB, Rohan TE (2008) Oral contraceptive use, hormone replacement therapy, reproductive history and risk of colorectal cancer in women. Int J Cancer 122(3): 643-646.

Kronenberg H, Williams RH (2010) Williams Textbook of Endocrinology. 10th edn, pp 796-810, Saunders/Elsevier: Philadelphia, PA, 2010.

Lin J, Zhang SM, Cook NR, Manson JE, Buring JE, Lee IM (2007) Oral contraceptives, reproductive factors, and risk of colorectal cancer among women in a prospective cohort study. Am J Epidemiol 165(7): 794-801.

Lin JH, Zhang SM, Rexrode KM, Manson JE, Chan AT, Wu K, Tworoger SS, Hankinson SE, Fuchs C, Gaziano JM, Buring JE, Giovannucci E (2013) Association between sex hormones and colorectal cancer risk in men and women. Clin Gastroenterol Hepatol 11(4): 419-424.

Luan NN, Wu L, Gong TT, Wang YL, Lin B, Wu QJ (2015) Nonlinear reduction in risk for colorectal cancer by oral contraceptive use: a metaanalysis of epidemiological studies. Cancer Causes Control 26(1): 65-78.

Martinez ME, Grodstein F, Giovannucci E, Colditz GA, Speizer FE, Hennekens C, Rosner B, Willett WC, Stampfer MJ (1997) A prospective study of reproductive factors, oral contraceptive use, and risk of colorectal cancer. Cancer Epidemiol Biomarkers Prev 6(1): 1-5.

McMichael AJ, Potter JD (1980) Reproduction, endogenous and exogenous sex hormones, and colon cancer: a review and hypothesis. J Natl Cancer Inst 65(6): 1201-1207.

Murphy N, Strickler HD, Stanczyk FZ, Xue X, Wassertheil-Smoller S, Rohan TE, Ho GYF, Anderson GL, Potter JD, Gunter MJ (2015) A prospective evaluation of endogenous sex hormone levels and colorectal cancer risk in postmenopausal women. J Natl Cancer Inst 107: pii: djv210.

Nanda K, Bastian LA, Hasselblad VF, Simel DL (1999) Hormone replacement therapy and the risk of colorectal cancer: a meta-analysis. Obstet Gynecol 93(5 Pt 2): 880-888.

Oshima CT, Wonraht DR, Catarino RM, Mattos D, Forones NM (1999) Estrogen and progesterone receptors in gastric and colorectal cancer. Hepatogastroenterology 46(30): 3155-3158.

Pischon T, Lahmann PH, Boeing H, Friedenreich C, Norat T, Tjønneland A, Halkjaer J, Overvad K, Clavel-Chapelon F, Boutron-Ruault MC, Guernec G, Bergmann MM, Linseisen J, Becker N, Trichopoulou A, Trichopoulos D, Sieri S, Palli D, Tumino R, Vineis P, Panico S, Peeters PHM, Bueno-deMesquita HB, Boshuizen HC, Van Guelpen B, Palmqvist R, Berglund G, Gonzalez CA, Dorronsoro M, Barricarte A, Navarro C, Martinez C, Quirós JR, Roddam A, Allen N, Bingham S, Khaw KT, Ferrari P, Kaaks R, Slimani N, Riboli E (2006) Body size and risk of colon and rectal cancer in the European Prospective Investigation Into Cancer and Nutrition (EPIC). J Natl Cancer Inst 98(13): 920-931.

Sakauchi F, Japan Collaborative Cohort Study for Evaluation of Cancer (2007) Reproductive history and health screening for women and mortality in the Japan Collaborative Cohort Study for Evaluation of Cancer (JACC). Asian Pac J Cancer Prev 8(Suppl): 129-134.
Shojania AM (1982) Oral contraceptives: effect of folate and vitamin B12 metabolism. Can Med Assoc J 126(3): 244-247.

Simon MS, Chlebowski RT, Wactawski-Wende J, Johnson KC, Muskovitz A, Kato I, Young A, Hubbell FA, Prentice RL (2012a) Estrogen plus progestin and colorectal cancer incidence and mortality. J Clin Oncol 30(32): 3983-3990.

Simon MS, Chlebowski RT, Wactawski-Wende J, Johnson KC, Muskovitz A, Kato I, Young A, Hubbell FA, Prentice RL (2012b) Estrogen plus progestin and colorectal cancer incidence and mortality. J Clin Oncol 30(32): 3983-3990.

The Women's Health Initiative Study Group (1998) Design of the Women's Health Initiative Clinical Trial and Observational Study. Control Clin Trials 19(1): 61-109.

Thrift AP, Gong J, Peters U, Chang-Claude J, Rudolph A, Slattery ML, Chan AT, Locke AE, Kahali B, Justice AE, Pers TH, Gallinger S, Hayes RB, Baron JA, Caan BJ, Ogino S, Berndt SI, Chanock SJ, Casey G, Haile RW, Du M, Harrison TA, Thornquist M, Duggan DJ, Le Marchand L, Lindor NM, Seminara D, Song M, Wu K, Thibodeau SN, Cotterchio M, Win AK, Jenkins MA, Hopper JL, Ulrich CM, Potter JD, Newcomb PA, Hoffmeister M, Brenner H, White E, Hsu L, Campbell PT (2015) Mendelian randomization study of body mass index and colorectal cancer risk. Cancer Epidemiol Biomarkers Prev 24(7): 1024-1031.

Tsilidis KK, Allen NE, Key TJ, Bakken K, Lund E, Berrino F, Fournier A, Olsen A, Tjonneland A, Overvad K, Boutron-Ruault MC, Clavel-Chapelon F, Byrnes G, Chajes V, Rinaldi S, Chang-Claude J, Kaaks R, Bergmann M, Boeing H, Koumantaki Y, Stasinopoulou G, Trichopoulou A, Palli D, Tagliabue G, Panico S, Tumino R, Vineis P, Bueno-de-Mesquita HB, van Duijnhoven FJB, van Gils CH, Peeters PHM, Rodriguez L, Gonzalez CA, Sanchez MJ, Chirlaque MD, Barricarte A, Dorronsoro M, Borgquist S, Manjer J, van Guelpen B, Hallmans G, Rodwell SA, Khaw KT, Norat T, Romaguera D, Riboli E (2010) Oral contraceptives, reproductive history and risk of colorectal cancer in the European Prospective Investigation into Cancer and Nutrition. Br J Cancer 103(11): 1755-1759.

Tsilidis KK, Kasimis JC, Lopez DS, Ntzani EE, Ioannidis JPA (2015) Type 2 diabetes and cancer: umbrella review of meta-analyses of observational studies. BMJ 350: g7607.

US Dept of Health and Human Services, Public Health Service National Institues of Health (1993) SEER Program: Comparitive Staging Guide for Cancer. version 1.1. NIH Publication 933640Washington, DC.

Zervoudakis A, Strickler HD, Park Y, Xue X, Hollenbeck A, Schatzkin A, Gunter MJ (2011) Reproductive history and risk of colorectal cancer in postmenopausal women. J Natl Cancer Inst 103(10): 826-834.

Zhang X, Wu K, Giovannucci EL, Ma J, Colditz GA, Fuchs CS, Willett WC, Stampfer MJ, Nimptsch K, Ogino S, Wei EK (2015) Early life body fatness and risk of colorectal cancer in US women and men-results from two large cohort studies. Cancer Epidemiol Biomarkers Prev 24(4): 690-697.

This work is published under the standard license to publish agreement. After 12 months the work will become freely available and the license terms will switch to a Creative Commons AttributionNonCommercial-Share Alike 4.0 Unported License. 